\title{
Managing dub with progesterone - locally or orally which is a better option?
}

\author{
Anu Pathak ${ }^{1}{ }^{*}$ Saroj Singh $^{1}$, Rachana Agarwal ${ }^{1}$, Charu Verma', ${ }^{1}$ ogesh K. Goyal ${ }^{2}$ \\ ${ }^{1}$ Department of Obstetrics and Gynaecology, ${ }^{2}$ Department of Pharmacology Sarojini Naidu Medical College Agra, \\ Uttar Pradesh, India
}

Received: 06 March 2016

Accepted: 04 April 2016

\author{
*Correspondence: \\ Dr. Anu Pathak, \\ E-mail: dr.anupathak@ymail.com
}

Copyright: ( $)$ the author(s), publisher and licensee Medip Academy. This is an open-access article distributed under the terms of the Creative Commons Attribution Non-Commercial License, which permits unrestricted non-commercial use, distribution, and reproduction in any medium, provided the original work is properly cited.

\begin{abstract}
Background: The levonorgestrel intrauterine system (LNG-IUS) is a safe and effective form of contraception used by millions of people worldwide. Other than this, it has many non-contraceptive benefits-treatments for dysfunctional uterine bleeding (DUB), fibroid uterus, endometriosis and endometrial hyperplasia.

Methods: A prospective longitudinal comparative study was carried out at department of obstetrics and gynaecology S.N. Medical College, Agra, Uttar Pradesh, India including 100 women of 20-45 years of age group (comparable in all aspects), with DUB. All cases were subjected to detailed history, examination and baseline investigationsHemoglobin $(\mathrm{Hb})$, endometrial aspiration, histopathology and ultrasound pelvis (along with endometrial thickness) and PBAC scoring before starting the treatment. Then cases were randomly allocated in two equal groups. In group A LNG-IUS was inserted. In group B cases were prescribed oral medroxy progesterone acetate $10 \mathrm{mg}$ bd from $5^{\text {th }}$ and $25^{\text {th }}$ day of menstrual cycle. Cases were followed at 1 month, 3 months and 6 months after starting treatment. At each follow-up visit primary outcome in terms of subjective assessment by patient, PBAC scores and secondary outcome as Hb levels and side-effects were recorded.

Results: Reduction in PBAC Scores, improvement in $\mathrm{Hb}$ and reduction in endometrial thickness were seen with both treatment modalities but results were significantly ( $\mathrm{p}<0.0001$ ) better with LNG-IUS group as compared to MPA. LNG-IUS was found to be more effective in endometrial hyperplasia and proliferative type of endometrium.

Conclusions: LNG-IUS is a good alternative to oral progesterone therapy for patients of DUB.
\end{abstract}

Keywords: LNG-IUS, DUB, Hb, PBAC Scores

\section{INTRODUCTION}

Abnormal uterine bleeding (AUB) is the commonest reason for women of all ages to consult their gynaecologist, particularly those at the extremes of their reproductive years and the problem has a considerable impact on health status and the quality of life of women it is second most common indication for hysterectomy after uterine leiomyoma. ${ }^{1}$ Abnormal uterine bleeding affects $10-30 \%$ of reproductive aged women and up to $50 \%$ of premenopausal women. ${ }^{2}$ Abnormal uterine bleeding (AUB) is sometimes mistaken as dysfunctional uterine bleeding(DUB) but AUB includes both organic and non- organic causes of uterine bleeding whereas DUB is irregular uterine bleeding that occurs in the absence of recognizable pelvic pathology, general medical disease, or pregnancy.

DUB is believed to occur in more than half of all women at least once during their reproductive age period. Up to $25 \%$ of women suffer at least one episode of DUB during their reproductive span.

Patients who experience repetitive episodes might experience significant consequences- carries the risk for iron deficiency anemia. Flow can be copious enough to 
require hospitalization. Chronic unopposed estrogenic stimulation of endometrial lining increases the risk of both endometrial hyperplasia and carcinoma. ${ }^{3}$

The ultimate cure is hysterectomy- though relatively safe with low mortality but one cannot deny the morbidity associated with this modality - like premature ovarian failure, cardiovascular and urinary dysfunction. Thus a majority of cases showing inclination towards the medical therapy as an alternative option., Antifibrinolytics, NSAIDS, progestrogens, danazol, ormeloxifene, GnRH analogues and levonorgestrelreleasing intrauterine system have all been used with varying results. For management of DUB drug of choice is progesterone. It may be used locally or orally. Orally it is available in various preparations like medroxy progesterone acetate, norethindrone acetate, etc. ${ }^{6}$ Locally progesterone is available as vaginal suppositories, gel and progesterone releasing intrauterine devices like LNGIUS. In cases of DUB LNG-IUS is used as an alternative treatment modality. It also acts by suppressing the endometrial proliferation.

The objective of this study was to study the efficacy and safety of levonorgestrel-intrauterine system and its comparison with oral medroxy progesterone acetate in dysfunctional uterine bleeding and its correlation with different endometrial patterns.

\section{METHODS}

The presented study was carried out in the department of obstetrics and gynaecology, Sarojini Naidu Medical College, Agra, Uttar Pradesh, India from October 2013 to October 2015. It is a prospective comparative study. 100 women of reproductive age group presenting with dysfunctional uterine bleeding, with good compliance and ready to follow instructions were included. All the selected cases were subjected to detailed history, clinical examination, routine investigations (CBC, LFT, KFT). Afterwards their USG whole abdomen and pelvis (measurement of endometrial thickness) was done. Along with this their endometrial aspirate and Pap smear were taken.

\section{Then following cases were excluded from the study}

- Pregnant or willing for issue

- With any organic pathology of pelvic organs

- Bleeding disorder, with cancer of genital tract

- With systemic diseases like- diabetes mellitus, hypertension, liver disease or any other serious medical illness

- Any established immunodeficiency.

All the selected patients were randomly divided into 2 groups each consisting 50 patients. Pretreatment PBAC Score was calculated for every case.
Group-A 50 cases selected in this group in whom LNGIUS was inserted within first seven days of menses.

Group-B 50 cases selected in this group are prescribed Oral medroxy progesterone acetate $10 \mathrm{mg}$ BD from day $5^{\text {th }}-25^{\text {th }}$ of the menstrual cycle.

The patients were called for follow up after 1 month, 3 months and 6 months. At each follow up assessment was done in terms of primary and secondary outcomes.

\section{Primary outcome studied as}

- Menstrual diary

- PBAC scores

- Subjective assessment of patient (regarding their general condition, their ability to do their routine activities, satisfaction effect on menstrual blood loss and acceptability, and thereafter their assessment was graded as mild or marked improvement, no improvement or further deterioration in the condition).

\section{Secondary outcome studied as}

- Hb levels

- Any side-effects e.g.; nausea and vomiting, breast tenderness, weight gain etc.

After 6 months USG pelvis was done to discern the change in endometrial thickness.

\section{RESULTS}

(Table 1) shows that cases in both groups were comparable in all aspects. The mean age in group A was $35.22+5.817$ years and in group B it was $35.88+5.32$ years. Most of the cases in both groups were multipara. The mean PBAC Score in group A was 242.88+93.36 and in group B it was $246+89.97$. The mean $\mathrm{Hb}$ in group A was $7.434+0.93 \mathrm{gm} \%$ and in group B was $7.466+1.04$ gm $\%$. The mean endometrial thickness in group A was $10.59+1.92 \mathrm{~mm}$ and in group B was $11.08+2.18 \mathrm{~mm}$.

Table 1: Patient profile in both groups.

\begin{tabular}{|lll|}
\hline Profile parameters & $\begin{array}{l}\text { Group A } \\
\text { (LNG group) }\end{array}$ & $\begin{array}{l}\text { Group B } \\
\text { (MPA) }\end{array}$ \\
\hline Mean age ( years) & $35.22 \pm 5.817$ & $35.88 \pm 5.32$ \\
\hline $\begin{array}{l}\text { Pretreatment } \\
\text { mean PBAC score }\end{array}$ & $242.88 \pm 93.36$ & $246 \pm 89.87$ \\
\hline $\begin{array}{l}\text { Pretreatment } \\
\text { mean Hb level (gm\%) }\end{array}$ & $7.434 \pm 0.933$ & $7.466 \pm 1.041$ \\
\hline $\begin{array}{l}\text { Pre-treatment mean } \\
\text { endometrial } \\
\text { thickness (mm) }\end{array}$ & $10.59 \pm 1.92$ & $11.08 \pm 2.18$ \\
\hline
\end{tabular}


(Table 2) shows distribution of cases according to PBAC Scores before initiating the therapy. (Table 3) compares the pre-treatment PBAC Scores with fall in mean PBAC Scores after 1, 3 and 6 months of treatment. The pretreatment mean PBAC Score in group A was $242.88 \pm 93.36$ and in group B it was $246.84 \pm 89.97$. After 6 months the mean reduction in PBAC Scores was $77.28 \pm 44.72$ whereas in group $B$ the mean reduction in PBAC Scores was 131 \pm 61.46 . (Table 4) shows that in group A after 6 months of treatment (86\%) cases reported with PBAC Scores $<100$ and in group B it was $36 \%$ cases.

(Table 5) shows the comparison of pre-treatment and after-treatment $\mathrm{Hb}$ levels. The mean pre-treatment $\mathrm{Hb}$ levels in group A and group B were 7.434 $\pm 0.933 \mathrm{gm} \%$ and $7.46 \pm 1.041 \mathrm{gm} \%$ respectively. After 6 months of treatment it increased by $2.17 \mathrm{gm} \%$ in group $\mathrm{A}$ and in group B by $0.81 \mathrm{gm} \%$. Similarly, (Table 6 ) compares the pre-treatment and after-treatment mean endometrial thickness. In group A pre-treatment it was $10.68 \pm 1.977$ $\mathrm{mm}$ and in group B it was $11.04 \pm 2.37 \mathrm{~mm}$. After 6 months of treatment it was reduced by $2.53 \mathrm{~mm}$ in group $\mathrm{A}$ and by $1.65 \mathrm{~mm}$ in group $\mathrm{B}$.

Table 2: Distribution of cases according to pre-treatment PBAC scores.

\begin{tabular}{|lllll|}
\hline \multirow{2}{*}{ PBAC Scores } & \multicolumn{2}{l}{$\begin{array}{l}\text { Group-A } \\
\text { (LNG-IUS) }\end{array}$} & $\begin{array}{l}\text { Group-B } \\
\text { (NDPA) }\end{array}$ \\
\cline { 2 - 5 } & Number & $\%$ & Number & $\%$ \\
\hline 100 & 00 & 00 & 00 & 00 \\
\hline $200-300$ & 30 & 60 & 28 & 56 \\
\hline $300-400$ & 10 & 20 & 12 & 24 \\
\hline$>400$ & 05 & 10 & 06 & 12 \\
\hline Total & 05 & 10 & 04 & 08 \\
\hline Mean \pm S.D. & $\mathbf{5 0}$ & $\mathbf{1 0 0}$ & $\mathbf{5 0}$ & $\mathbf{1 0}$ \\
\hline
\end{tabular}

Table 3: Mean PBAC scores pre-treatment and after 1, 3 and 6 months of treatment in both groups.

\begin{tabular}{|lllll|}
\hline Group & Pre-treatment & After 1 month & After 3 months & After 6 months \\
\hline $\begin{array}{l}\text { Group a } \\
\text { (LNG-IUS) }\end{array}$ & $242.88 \pm 93.36$ & $145.32 \pm 79.29$ & $108.6 \pm 70.887$ & $77.28 \pm 44.72$ \\
\hline $\begin{array}{l}\text { Group-b } \\
\text { (MDPA) }\end{array}$ & $246.84 \pm 89.97$ & $206.52 \pm 84.68$ & $166.1 \pm 77.78$ & $131 \pm 61.46$ \\
\hline
\end{tabular}

Table 4: Achievement of PBAC scores $<100$ after therapy.

\begin{tabular}{|c|c|c|c|c|}
\hline & \multicolumn{2}{|c|}{$\begin{array}{l}\text { PBAC score } \\
<100 \text { in } \\
\text { group-A } \\
\text { (LNG-IUS) }\end{array}$} & \multicolumn{2}{|c|}{$\begin{array}{c}\text { PBAC }<100 \text { in } \\
\text { group-B } \\
(\mathrm{MDPA})\end{array}$} \\
\hline & No. & $\%$ & No. & $\%$ \\
\hline Pre-treatment & 00 & 00 & 00 & 00 \\
\hline After 1 Month & 12 & 24 & 04 & 08 \\
\hline After 3 Months & 30 & 60 & 15 & 30 \\
\hline After 6 Months & 43 & 86 & 18 & 36 \\
\hline
\end{tabular}

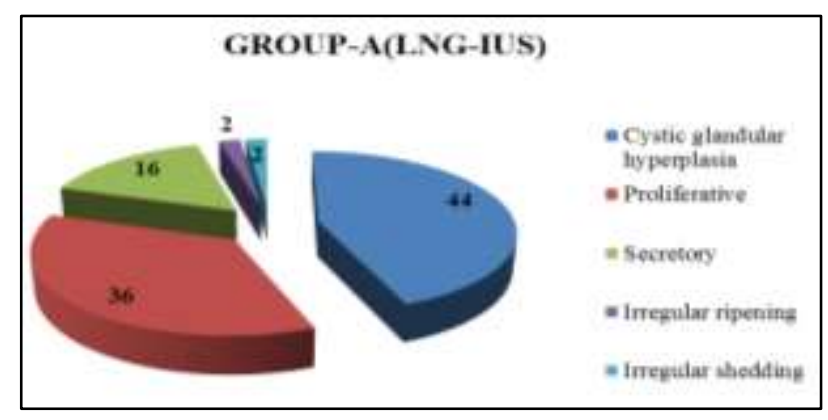

Figure 1: Distribution of cases according to type of endometrium on histology in group A.

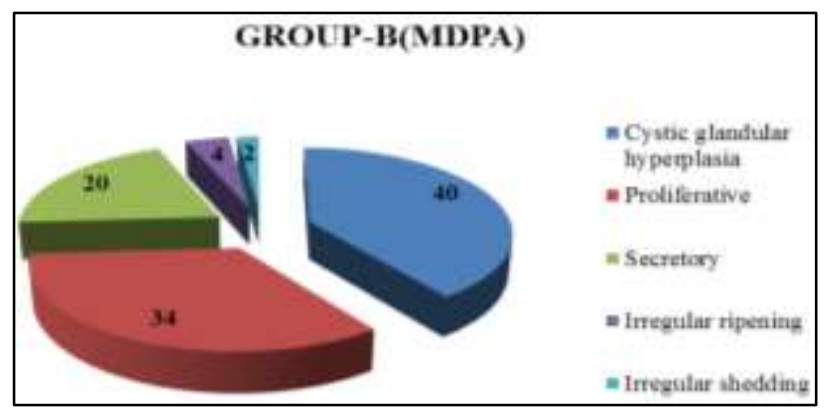

Figure 2: Distribution of cases according to type of endometrium on histology in group $B$.

(Figure 1-2) shows the distribution of cases according to histology pattern seen in both groups- most common endometrial pattern found was cystic glandular hyperplasia, followed by proliferative and secretory type of endometrium. Few cases of irregular type of endometrium were also seen. (Figure 3) shows that after 6 months of treatment in group A 90\% cases and in group B 50\% of cases reported marked improvement, $5 \%$ cases in group A and $44 \%$ of cases in group B with mild improvement. In group B 4\% cases reported with no improvement and $2 \%$ of cases shown further deterioration whereas no such case was reported in group A. During the study period of 6 months certain side- 
effects were reported in both groups. In group A $4 \%$ cases developed amenorrhoea and $26 \%$ of cases developed hypo menorrhoea, which was even a desired effect a. In group B most of the cases complained of certain distressing systemic side-effects $-20 \%$ cases with nausea and vomiting, 6\% cases with breast tenderness, $8 \%$ cases developed hypo menorrhoea, $20 \%$ cases with breakthrough bleeding and $18 \%$ cases complained of spotting.

Table 5: Mean Hb levels pre-treatment, after 1 month, after 3 months and after 6 months of treatment.

\begin{tabular}{|c|c|c|c|c|}
\hline \multirow[b]{2}{*}{ Group } & \multicolumn{4}{|c|}{ Hb levels (gm \%) } \\
\hline & Pre-treatment & After 1 month of treatment & $\begin{array}{l}\text { After } 3 \text { months } \\
\text { of treatment }\end{array}$ & $\begin{array}{l}\text { After } 6 \text { months } \\
\text { of treatment }\end{array}$ \\
\hline $\begin{array}{l}\text { Group A (LNG- } \\
\text { IUS) }\end{array}$ & $7.434 \pm 0.933$ & $8.16 \pm 0.98$ & $8.958 \pm 0.88$ & $9.604 \pm 0.857$ \\
\hline Group-B (MDPA) & $7.466 \pm 1.041$ & $7.806 \pm 1.02$ & $7.992 \pm 1.0078$ & $8.27 \pm 1.03$ \\
\hline
\end{tabular}

Table 6: Mean endometrial thickness pre-treatment and after 6 months of treatment in both groups.

\begin{tabular}{|lll|}
\hline Group & $\begin{array}{l}\text { Endometrial thickness }(\mathrm{mm}) \\
\text { Pre- } \\
\text { treatment }\end{array}$ & $\begin{array}{l}\text { After 6 month } \\
\text { treatment }\end{array}$ \\
\hline $\begin{array}{l}\text { Group A } \\
\text { (LNG-IUS) }\end{array}$ & $10.68 \pm 1.977$ & $8.154 \pm 1.71$ \\
\hline $\begin{array}{l}\text { Group B } \\
\text { (MDPA) }\end{array}$ & $11.04 \pm 2.187$ & $9.39 \pm 2.37$ \\
\hline
\end{tabular}

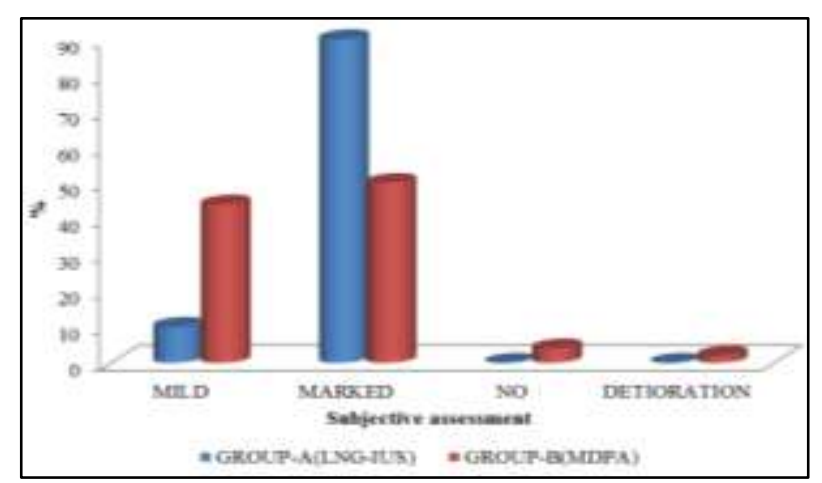

Figure 3: Subjective assessment after 6 months of treatment in both groups.

\section{DISCUSSION}

In present study, the mean age in group A (LNG-IUS) was $35.22 \pm 5.817$ years and in group B (MPA) it was $35.88 \pm 5.32$ years which were comparable to that used in other studies. In a similar study by Naeemaet al mean age was $35.98 \pm 7.66$ Years. ${ }^{7}$

In this study all cases were having PBAC >100 similarly in an article published on a randomized controlled trial conducted by Robert et al all patients with menorrhagia were having PBAC Scores $>120{ }^{8}$ At the end of present study after 6 months treatment both the treatment modalities were found effective in reducing PBAC scores but reduction was significantly better with LNG-IUS in group A (reduced by $68.18 \%$ ). This was comparable to the results of study conducted by Kuck et al (comparing LNG-IUS and MPA in premenopausal menorrhagia). ${ }^{9}$ In another 1 year follow up study by Shaban et al comparing LNG-IUS with low dose OCP for idiopathic menorrhagia reported a reduction of $86.6 \pm 17 \%$ in PBAC scores. ${ }^{10}$

In present study $86 \%$ of cases achieved PBAC Scores $<100$ after 6 months in group A whereas in group B only $36 \%$ of cases achieved the desired effect. The results obtained were comparable to those achieved by B. Chattopadhyaya (73.6\%) in similar study. ${ }^{11}$

Like PBAC Scores, mean $\mathrm{Hb}$ levels increased and mean endometrial thickness was reduced after treatment in both groups but results were significantly better with LNGIUS. In group A increase in mean $\mathrm{Hb}$ was by $2.17 \mathrm{gm} \%$ and in group B it was by $0.81 \mathrm{gm} \%$. In group A the mean reduction in endometrial thickness was by $2.53 \mathrm{~mm}$ and in group B by $1.65 \mathrm{~mm}$. In a similar study by Alka K et al the increase in mean $\mathrm{Hb}$ was by $1.06 \pm 1.7 \mathrm{gm} \%$ and reduction in mean endometrial thickness was by $3.4 \pm 3.53$ mm. ${ }^{12}$

The commonest histopathological pattern seen in this study was endometrial hyperplasia. In a study by Sajitha $\mathrm{K}$ et al concluded that most common histopathological finding was endometrial hyperplasia. ${ }^{13}$ Similar results were reported from a three years clinicopathological study by Patil $\mathrm{R}$ et. ${ }^{14}$ In this study histopathologically commonest endometrial pattern associated with DUB seen was endometrial hyperplasia followed by proliferative endometrium.

$4 \%$ of the cases in group A reported with amenorrhea and $26 \%$ cases developed hypomenorrhoea .In group B $8 \%$ cases developed hypomenorrhoea. In study by Alka K et al. $^{12}(28.57 \%)$ developed amenorrhea after 1 year with LNG-IUS. In a similar study by Taru $\mathrm{G}$ et al $33.87 \%$ cases using LNG-IUS reported amenorrhoea. ${ }^{15}$ 


\section{CONCLUSIONS}

By analysing the results of present study, LNG-IUS seems to be better treatment modality for DUB in comparison of oral MPA. LNG IUS can be a good alternative to the medical and surgical treatment for menorrhagia in DUB with good efficacy and lesser sideeffects. It dramatically reduces the amount of bleeding in a few months. LNG IUS had better patient satisfaction rate. However to get more conclusive results longer studies with larger sample size are suggested.

Funding: No funding sources

Conflict of interest: None declared

Ethical approval: The study was approved by the Institutional Ethics Committee

\section{REFERENCES}

1. Palep Singh, Prentice A. Epidemiology of abnormal uterine bleeding. Best practice and research clinical obstetrics and gynaecology. 2007;21(6):887-90.

2. Ann LM, Jay Mc G. Menstruation and menstrual disorder. In: Wshaw R, Soutter WP, Stuart L. Stauton Gynaecology $3^{\text {rd }}$ ed. UK, Churchill Livingston; 2003:459-473.

3. Behera MA. Dysfunctional uteine bleeding. Richard Scott Lucidi Practice essentials, emedicine. medscape. com/article/ 257007-ov

4. Coutler A, Kelland J, Peto V, Rees MC. Treating menorrhagia in primary care. An overview of drug trials and a survey of prescribing practice. Int J Tech Assess Health Care. 1995;11:456-71.

5. Winsor SHM, Fisher S, Hahn PM, Reid RL. Retrospective evaluation of long term outcomes following conservative management of menorrhagia in ovulatory women. J Soc Obstet Gynaecol Can. 1999;2:155-63.

6. National collaborating centre for women's and children's health, national institute of clinical excellence. Heavy menstrual bleeding. Clinical guideline. London. RCOG Press; 2007.

7. Naeema U, Faheem F. LNG-IUS in menorrhagia : a three year follow up study. Journal of postgraduate medical institute. 2010;26(1):79-83.

8. Robert W. Symonds IM, Tamizian O, Chaplain J, Mukhopadhyay S. Randomised comparative trial of thermal balloon ablation and levonorgestrel intrauterine system in patients with idiopathic menorrhagia. Australian and New Zealand Journal of Obstetrics and Gynaecology. 2007;47(4):335-40.

9. Kucuk T, Ertan K. Contiuous oral or intramuscular medroxy progesterone acetate versus LNG-IUS in treatment of perimenopausal menorrhagia .clinical and experimental obstetrics and gynaecology. 2008;35(1):57-60.

10. Shaaban MM, Zakherah MS, El-Nashar SA, Sayed GH. Levonorgestrel-releasing intrauterine system compared to low dose combined oral contraceptive pills for idiopathic menorrhagia: a randomized clinical trial. Contraception. 2011;83(1):48-54.

11. Chattopdhyay B, Nigam A, Goswami S, Chakravarty PS. Clinical outcome of levonorgestrel intra-uterine system in idiopathic menorrhagia. Eur Rev Med Pharmacol Sci. 2011;15(7):764-8.

12. Kriplani A, Singh BM, Lal S, Agarwal N. Efficacy, acceptability and side effects of the levonorgestrel intrauterine system for menorrhagia. International Journal of Gynecology and Obstetrics. (2007);97(3): 190-4.

13. Sajitha K, Padma SK, Shetty KJ, Kishanprasad HL, Permi HS, Hegde P. Study of histopathological patterns of endometrium in abnormal uterine bleeding. CHRISMED J Health Res. 2014;1:76-81.

14. Patil R, Patil RK, Andola SK, Laheru V, Bhandar M. Histopathological spectrum of endometrium in dysfuctional uterine bleeding. 2013;4(1): 2798-2801.

15. Taru G, Nupur G, Sangeeta G, Pushpa B, Jyoti J, Sushma K. Levonorgestrel intrauterine system (LNG IUS) in menorrahgia: a follow-up study. Open Journal of Obstetrics and Gynecology. 2014;4:190-6.

Cite this article as: Pathak A, Singh S, Agarwal R, Verma C, Goyal YK. Managing dub with progesterone - locally or orally which is a better option? Int J Reprod Contracept Obstet Gynecol 2016;5:1483-7. 